\title{
Cenplesto
}

\section{A comunicação da ciência em eventos científicos na visão de pesquisadores}

\author{
Maria Cristina Piumbato Innocentini Hayashi \\ Doutora; Universidade Federal de São Carlos (UFSCar), São Carlos, SP, Brasil; \\ dmch@ufscar.br \\ Vera Aparecida Lui Guimarães \\ Doutoranda; Universidade Federal de São Carlos (UFSCar), São Carlos, SP, Brasil; \\ veralui@ufscar.br
}

Resumo: Esse artigo apresenta os resultados obtidos por meio de uma pesquisa empírica sobre o significado que a comunicação científica em eventos assume para uma comunidade de pesquisadores de diferentes áreas da ciência. Do ponto de vista metodológico trata-se de um estudo exploratório e descritivo, de cunho explicativo com abordagem quanti-qualitativa. A população investigada foi composta por 150 pesquisadores vinculados a uma instituição federal de ensino superior do interior do estado de São Paulo, e o instrumento para a coleta de dados foi um questionário online. Os dados empíricos da pesquisa foram categorizados e analisados à luz dos referenciais teóricos da Sociologia da Ciência e da Ciência da Informação. Os resultados evidenciaram especificidades das diferentes áreas do conhecimento em relação à comunicação em eventos científicos confirmando que esse meio de divulgação ainda é um dos mais utilizados pelos pesquisadores, e se constituem em um bom termômetro para verificar a aceitação pelos pares.

Palavras-chave: Eventos científicos. Comunicação da ciência. Sociologia da ciência. Comunicação informal. Divulgação científica.

\section{Introdução}

A construção do conhecimento científico é um processo social que ocorre a partir de resultados anteriores, viabilizado por meio de processos de comunicação científica. Isso implica que a ciência depende dos processos de comunicação para disseminar aos pares e para divulgar aos leigos tudo o que é produzido pela comunidade de pesquisadores que a compõem. Na visão de Ziman (2000)

O sistema formal da ciência é apenas um dos muitos canais através dos quais os resultados da investigação fluem para fora dos 


\begin{abstract}
laboratórios ou bibliotecas em que são produzidos. É acompanhado por processos informais que se estendem à sociedade. Cientistas conversam incessantemente e compulsivamente entre si - no laboratório, nos corredores, ao redor da mesa do almoço e qualquer lugar em que eles se encontram. Eles também gastam uma grande parte do tempo dando palestras e ouvindo uns aos outros, em seminários, conferências e outras reuniões. Alguns deles tentam melhorar "a compreensão pública da ciência", escrevendo livros populares, falando no rádio e aparecendo na televisão. (ZIMAN, 2000, p.34, tradução nossa)
\end{abstract}

A comunicação científica diz respeito a um ciclo de atividades que incluem a produção, a disseminação e o uso da informação. O conceito de comunicação científica conforme formulado por Garvey (1979, p.10) envolve o "espectro total de atividades informacionais que ocorrem entre os produtores de informação científica, desde o momento em que eles iniciam suas pesquisas até a publicação de seus resultados e sua aceitação e integração a um corpo de conhecimento". Para realizar o processo de comunicação os pesquisadores podem utilizar os canais de comunicação formais, tais como a publicação em livros e capítulos e artigos em periódicos científicos da área, e também os canais informais, principalmente por meio da apresentação de trabalhos em eventos científicos. No segundo caso, ao participarem dos eventos específicos os pesquisadores integram os "colégios invisíveis" - conceito formulado por Price (1961) e ampliado por Crane (1972) - constituindo o que hoje se conhece pela denominação por "redes de colaboração científica". O que se observa durante sua realização é a troca de experiências e conhecimento entre os pares pesquisadores e seus demais colegas, que são os autores e coautores dos trabalhos apresentados.

Os eventos científicos também são os fóruns mais comuns para os pesquisadores comunicarem suas descobertas científicas e discutirem os achados de suas pesquisas, conforme argumentam Martens e Saretzki (1993) em um estudo que buscou descrever os padrões de comunicação em ciência e tecnologia. Os autores mostraram a importância das conferências, cursos, workshops, e outros tipos de reuniões científicas, especialmente em domínios multidisciplinares.

Por sua vez, Söderqvist e Silverstein (1999, p.102) chamam a atenção para o fato de que "dada a função catalizadora dos eventos na ciência ao longo 
da história moderna, é surpreendente que eles tenham sido negligenciados como um tópico de pesquisa independente por sociólogos e historiadores da ciência”, o que evidencia a importância da presente pesquisa. Além disso, eventos acadêmicos revelam frentes de pesquisa e oferecem oportunidades para identificar resultados atualizados de pesquisas científicas. Em uma breve revisão de literatura sobre a importância dos eventos científicos, Jeong e Kim (2010) sintetizaram os estudos realizados sob essa temática:

Kranakis e Leydesdorff (1989) demonstraram a importância de eventos acadêmicos como fontes, em particular no que diz respeito ao surgimento e crescimento da ciência. Martens e Saretzki (1993, 1994) demonstraram que a análise de anais de eventos tem algumas vantagens sobre as atuais abordagens bibliométricas, porque não são restringidos pelo lapso de tempo de bases de dados bibliográficas. Synnestvedt e Chen (2003) visualizaram o domínio da informática médica utilizando o American Medical Informatics Association Symposium Proceedings. Söderqvist e Silverstein (1994) mapearam a estrutura sub-disciplinar de um domínio científico através da frequência de dados dos participantes em eventos [...]. Outros estudos salientam que os anais têm maior importância do que artigos na transferência de conhecimento (Glänzel et al 2006; Godin 1998; Lisée e Larivière 2008; Matsuo et al., 2003). Na verdade, em informática biomédica o trabalho acadêmico mais atual tende a aparecer em eventos visando a mais rápida divulgação do conhecimento. (JEONG; KIM, 2010, p. 543, tradução nossa).

Ao analisar os cientistas que constituem "a elite dirigente de disciplinas científicas" e frequentemente participam de eventos internacionais, as pesquisas realizadas por Söderqvist e Silverstein (1994) mostram que há uma forte correlação entre a frequência de participação em eventos científicos e a reputação acadêmica. Esses autores também consideram que

\footnotetext{
Hoje, os eventos não só proporcionam arenas onde os pesquisadores podem trocar informação sobre novas teorias, resultados e técnicas. Por analogia com as disciplinas científicas, eles também podem ser vistos como unidades político-retóricas - arenas de negociação daquilo que se constituem os tópicos de pesquisa interessantes, para delimitação de territórios cognitivos e para a distribuição de status científico e papéis dentro da hierarquia disciplinar. (SÖDERQVIST; SILVERSTEIN, 1999, p. 101, tradução nossa).
}

Essas breves considerações teóricas introduzem o tema do artigo - a comunicação científica em eventos - e o objetivo do estudo relatado: investigar a comunicação da ciência em eventos científicos, buscando compreender o seu 
significado de acordo com a visão de pesquisadores de diferentes áreas de conhecimento e dos contextos de produção da ciência em uma instituição federal de ensino superior.

Além dessa introdução o artigo está estruturado em mais três partes, que apresentam, respectivamente: os procedimentos metodológicos adotados, os resultados obtidos na pesquisa e as considerações finais.

\section{Procedimentos metodológicos}

A pesquisa realizada pode ser caracterizada como de cunho exploratóriodescritivo, pois visou obter informações e descrições mais precisas a respeito de um problema ou de uma situação, com o objetivo de torná-lo explícito descrevendo características de determinada população ou fenômeno. Além disso, também pode ser caracterizada como uma pesquisa explicativa, pois visa identificar os fatores que determinam ou contribuem para a ocorrência dos fenômenos, aprofundando o conhecimento da realidade e explicando a causa, "o porquê" das coisas. Em relação aos procedimentos técnicos, a pesquisa também pode ser caracterizada como um survey, pois ao perguntar "às pessoas sobre o seu comportamento, o que fazem e fizeram e sobre os seus estados subjetivos, o que, por exemplo, pensam e pensaram" (GÜNTHER, 2006, p. 201), possibilitou conhecer as práticas, valores e comportamentos de uma comunidade acadêmica em particular em relação à comunicação científica.

Os procedimentos metodológicos foram executados em três etapas distintas: a) delineamento da pesquisa, seguida da identificação, seleção dos participantes e definição de um plano amostral para coleta de dados; b) coleta de dados, realizada por meio de um questionário online elaborado com questões extraídas dos construtos teóricos da ciência acadêmica e comunidade científica, conforme o referencial teórico da pesquisa, contemplando hábitos, práticas, valores e comportamentos dessa comunidade e também sobre o que representam os eventos na carreira dos pesquisadores que integraram a amostra de respondentes; c) descrição, análise e interpretação dos resultados, por meio da estatística descritiva, confrontando-os com o referencial teórico utilizado na 
pesquisa.

O questionário online foi composto por 43 questões distribuídas em três seções, assim configuradas: Seção A - Caracterização da amostra, composta por oito questões que possibilitam caracterizar os docentes selecionados na amostra, com questões referentes à identificação da unidade departamental, categoria funcional docente, gênero, estado civil, filhos abaixo de 16 anos, faixa etária e tempo no nível de titulação mais elevado; Seção B - Os eventos científicos, constituída por 19 questões ${ }^{1}$ que abordaram inúmeros aspectos da comunicação científica realizada em eventos científicos; Seção C - A comunidade científica, contendo 16 questões visando conhecer a opinião dos respondentes sobre situações relacionadas ao fazer científico.

É importante salientar que a pesquisa foi aprovada pelo Comitê de Ética em Pesquisa e antes de iniciar o questionário os docentes assinaram um Termo de Consentimento Livre e Esclarecido contendo informações sobre os objetivos da pesquisa, a possibilidade de desistência da participação a qualquer momento, o sigilo da identidade dos participantes e a forma de preenchimento do instrumento de coleta de dados.

Os participantes da pesquisa foram selecionados entre os integrantes do corpo docente que desenvolve atividades de ensino, pesquisa e extensão em regime de dedicação exclusiva em uma instituição federal de ensino superior localizada no estado de São Paulo. Esses participantes foram agrupados de acordo com oito grandes áreas de conhecimento definidas pela Coordenação de Aperfeiçoamento de Pessoal de Nível Superior (CAPES) e Conselho Nacional de Pesquisa (CNPq): Ciências Exatas e da Terra; Ciências Biológicas; Engenharias; Ciências da Saúde; Ciências Agrárias; Ciências Sociais Aplicadas; Ciências Humanas; Linguística, Letras e Artes.

O plano amostral da pesquisa foi baseado em um procedimento de amostragem aleatória estratificada proporcional ao tamanho dos estratos, pois esse tipo de amostra tem a vantagem de garantir que todos os elementos dos vários subgrupos da população sejam representados, especialmente os com menor incidência na população (COZBY, 2003). Os estratos (áreas, gênero e categoria funcional) foram estabelecidos de modo a viabilizar a presença na 
amostra, via sorteio, de uma quantidade representativa de elementos característicos da população alvo. A amostra final foi composta por 324 participantes, distribuídos de acordo com o gênero dos participantes (homens e mulheres), as categoriais funcionais (ativos e inativos), o recebimento ou não de bolsas de produtividade em pesquisa do $\mathrm{CNPq}$, e a vinculação às unidades departamentais da instituição. O detalhamento da distribuição da amostra final nas áreas de conhecimento e de atuação dos participantes de acordo a vinculação departamental pode ser observado na Tabela 1 .

Tabela 1 - Amostra final de acordo com as áreas de conhecimento e de atuação dos pesquisadores

\begin{tabular}{l|l|c}
\hline \multicolumn{1}{c|}{ Áreas de conhecimento* } & \multicolumn{1}{|c}{ Áreas de atuação } & Participantes \\
\hline $\begin{array}{l}\text { EXA: Ciências Exatas e da } \\
\text { Terra }\end{array}$ & $\begin{array}{l}\text { Física, Química, Computação, Matemática, } \\
\text { Estatística }\end{array}$ & 80 \\
\hline BIO: Ciências Biológicas & $\begin{array}{l}\text { Genética, Botânica, Zoologia, Ecologia, } \\
\text { Fisiologia. }\end{array}$ & 41 \\
\hline ENG: Engenharias & Civil, Materiais, Química, Produção. & 57 \\
\hline SAU: Ciências da Saúde & $\begin{array}{l}\text { Medicina, Enfermagem, Terapia } \\
\text { Ocupacional, Fisioterapia, Educação Física. }\end{array}$ & 44 \\
\hline AGR: Ciências Agrárias & Agronomia, Engenharia Agrícola. & 11 \\
\hline $\begin{array}{l}\text { CSA: Ciências Sociais } \\
\text { Aplicadas }\end{array}$ & $\begin{array}{l}\text { Ciência da Informação, Turismo, Economia, } \\
\text { Administração. }\end{array}$ & 23 \\
\hline CHU: Ciências Humanas & $\begin{array}{l}\text { Educação, Psicologia, Sociologia, Filosofia, } \\
\text { História, Geografia. }\end{array}$ & 47 \\
\hline $\begin{array}{l}\text { LLA: Linguística, Letras e } \\
\text { Artes }\end{array}$ & Linguística, Letras, Artes. & 21 \\
\hline
\end{tabular}

(*) As siglas das áreas de conhecimento serão utilizadas na apresentação dos resultados. Fonte: Dados da pesquisa. Elaborado pelas autoras

A coleta de dados ocorreu por meio de cinco chamadas aos selecionados na amostra para a participação na pesquisa no período compreendido entre 17 de fevereiro e 25 de abril de 2011. Foram enviadas mensagens adicionais durante as chamadas reafirmando a colaboração na realização da pesquisa e enfatizando a importância de obtermos as respostas dos participantes dos estratos que ainda não tinham alcançado o percentual mínimo estatístico de $30 \%$.

Embora não haja consenso na literatura científica (BARUCH, 1999; SHIH; FAN, 2009) quanto ao índice ideal de respostas de questionários, autores como Weible e Wallace (1998) relatam que para pesquisas por e-mail off-line a 
taxa de retorno é de $29,8 \%$ e de $32,7 \%$ com os questionários no formulário online, enquanto que para Sheehan e Hoy (1999) a taxa de respostas é de $24 \%$. Para questionários divulgados via e-mails Cunha, Salluh e França (2010) situam a taxa de retorno na faixa entre 20 a $30 \%$. Conforme mostram os dados da Tabela 2 a taxa de respostas obtidas por área de acordo com os 150 participantes atingiu o índice total de $46,3 \%$ compatível com a taxa de retorno acima de $31,25 \%$ considerada como aceitável por Wu et al (2004).

Tabela 2 - Distribuição dos participantes, respondentes e taxa de respostas por área

\begin{tabular}{c|c|c|c}
\hline Áreas & $\begin{array}{c}\text { Participantes da } \\
\text { amostra }\end{array}$ & Respondentes & $\begin{array}{c}\text { Taxa de Resposta } \\
\text { por área (\%) }\end{array}$ \\
\hline EXA & 80 & 34 & 42,5 \\
\hline BIO & 41 & 19 & 46,3 \\
\hline ENG & 57 & 27 & 47,4 \\
\hline SAU & 44 & 21 & 47,7 \\
\hline AGR & 11 & 5 & 45,4 \\
\hline CSA & 23 & 13 & 56,5 \\
\hline CHU & 47 & 23 & 48,9 \\
\hline LLA & 21 & 8 & 38,1 \\
\hline Total & $\mathbf{3 2 4}$ & $\mathbf{1 5 0}$ & $\mathbf{4 6 , 3}$ \\
\hline
\end{tabular}

Fonte: Dados da pesquisa. Elaborado pelas autoras.

Em face da literatura científica sobre a taxa de respostas de questionários online, acreditamos ter havido representatividade no índice final de respostas obtidas. O próximo tópico apresenta os resultados da pesquisa a partir das respostas às 19 questões sobre eventos científicos formuladas na seção B do questionário.

\section{Os eventos científicos na visão dos pesquisadores}

Em termos de abrangência os eventos científicos podem ser tanto locais, quanto nacionais ou internacionais, sendo comumente denominados como Congressos, Simpósios, Encontros, etc. Para sua realização são constituídas diversas comissões - Organizadora, Científica, de Apoio Técnico, etc. - compostas por representantes da área de especialização do evento.

A comunicação em eventos científicos pode ser apresentada nos formatos de trabalhos completos ou de resumos, expostos oralmente ou por meio de painéis (pôsteres), enquanto que a divulgação da produção científica 
oriunda dos trabalhos apresentados ocorre nos anais dos eventos, que podem trazer o texto integral ou apenas os resumos das comunicações e pôsteres, e eventualmente, também pode ocorrer divulgação em números especiais de revistas da área de especialização do evento.

Para melhor visualização dos resultados obtidos na pesquisa as respostas dos pesquisadores sobre eventos científicos foram organizadas em subseções específicas deste tópico.

\subsection{Participação e organização de eventos científicos}

Na pesquisa realizada os participantes foram questionados quanto à importância dos diversos tipos de atividades relacionadas aos eventos científicos - a apresentação de trabalhos, a participação como palestrante ou ouvinte, a organização de evento nacional ou internacional -, conforme mostram os dados da Tabela 3.

Tabela 3 - Tipos de atividades em eventos científicos

\begin{tabular}{|c|c|c|c|c|c|c|c|c|c|}
\hline \multirow[b]{2}{*}{ Atividades } & \multicolumn{9}{|c|}{ Valores obtidos (\%) } \\
\hline & CHU & AGR & CSA & SAU & LLA & EXA & ENG & BIO & $\begin{array}{c}\text { Respondentes } \\
(\%)\end{array}$ \\
\hline $\begin{array}{l}\text { Apresentação de } \\
\text { trabalho(s) em evento(s) }\end{array}$ & 100,0 & 100,0 & 100,0 & 95,2 & 87,5 & 85,2 & 85,1 & 84,2 & $136(90,6)$ \\
\hline $\begin{array}{l}\text { Participação em evento(s) } \\
\text { como palestrante }\end{array}$ & 86,9 & 80,0 & 61,5 & 80,9 & 50,0 & 58,8 & 55,55 & 78,9 & $103(68,6)$ \\
\hline $\begin{array}{l}\text { Participação em evento(s) } \\
\text { apenas como ouvinte }\end{array}$ & 47,8 & 80,0 & 61,5 & 90,4 & 62,5 & 44,1 & 48,1 & 47,3 & $84(56,0)$ \\
\hline $\begin{array}{l}\text { Organização de evento(s) } \\
\text { nacional }\end{array}$ & 56,5 & 40,0 & 38,4 & 38,0 & 50,0 & 29,4 & 40,7 & 31,5 & $59(40,0)$ \\
\hline $\begin{array}{l}\text { Organização de evento(s) } \\
\text { internacional }\end{array}$ & 13,0 & 0 & 0 & 4,7 & 0 & 8,8 & 22,2 & 5,2 & $18(12,0)$ \\
\hline
\end{tabular}

Fonte: Dados da pesquisa. Elaborado pelas autoras.

A resposta que alcançou maior percentual $(90,6 \%)$ em todas as áreas foi apresentação de trabalho em eventos, com 136 respondentes. As atividades de participação de eventos como palestrante foi destaque nas áreas CHU, SAU, AGR e BIO, enquanto que a participação em eventos como ouvintes obteve maiores percentuais nas áreas SAU e AGR.

A importância atribuída aos eventos também pode ser verificada pelo 
alto índice $(40 \%)$ de pesquisadores que responderam afirmativamente terem participado da organização de evento nacional, com destaque para as áreas CHU e LLA. Já a área de ENG se destacou na organização de evento internacional, com 22,2\% das respostas seguida pelas áreas CHU (13\%), EXA $(8,8 \%)$, BIO $(5,2 \%)$ e SAU $(4,7 \%)$ sendo que os respondentes das demais áreas não participaram e/ou organizaram eventos internacionais. Foram, neste quesito, $18(12 \%)$ os respondentes que participaram da organização de evento internacional de sua área.

Por sua vez, as respostas sobre a frequência média anual de participação nos eventos científicos nacionais podem ser visualizadas na Tabela 4 que apresenta a frequência média percentual de participação dos respondentes de acordo com as oito áreas do conhecimento.

Tabela 4 - Frequência de participação em eventos nacionais

\begin{tabular}{c|c|c|c|c|c|c|c|c|c}
\hline \multirow{2}{*}{ Frequência } & \multicolumn{7}{c}{ Valores obtidos (\%) } \\
\cline { 2 - 10 } & BIO & EXA & ENG & AGR & CSA & SAU & CHU & LLA & $\begin{array}{c}\text { Respondentes } \\
(\%)\end{array}$ \\
\hline 1 a 2 vezes & 94,7 & 82,3 & 74,0 & 60,0 & 53,8 & 52,3 & 52,1 & 37,5 & $102(68,0)$ \\
\hline 3 vezes & 0 & 8,8 & 22,2 & 40,0 & 15,3 & 42,8 & 30,4 & 12,5 & $30(20,0)$ \\
\hline 4 vezes & 0 & 5,8 & 3,7 & 0 & 30,7 & 0 & 4,3 & 37,5 & $11(7,3)$ \\
\hline + que 4 vezes & 5,2 & 0 & 0 & 0 & 0 & 4,7 & 13,0 & 0 & $5(3,3)$ \\
\hline Nenhuma & 0 & 2,9 & 0 & 0 & 0 & 0 & 0 & 12,5 & $2(1,3)$ \\
\hline
\end{tabular}

Fonte: Dados da pesquisa. Elaborado pelas autoras.

A maioria das áreas participa majoritariamente de um a dois eventos nacionais anualmente, com sete áreas obtendo índices superiores a 52,1\%, à exceção da LLA que obteve 37,5\%. Foram 102 respondentes representando 68\% entre as diversas áreas. Os destaques são para as áreas de BIO (94,7\%), EXA (82,3\%) e ENG (74,0\%), porém, nota-se que as áreas de SAU (42,8\%), AGR (40\%), e CHU (30,4\%) participam expressivamente em até três eventos por ano e que apenas a área CHU (13,0\%) participou em eventos mais de quatro vezes ao ano. Merece destaque a área LLA que obteve a mesma frequência de participação (37,5\%) nas opções 1 a 2 vezes e de 4 vezes anuais. Do total de respondentes (150), apenas 2 responderam não ter participado de nenhum 
evento.

Na Tabela 5 é possível visualizar a frequência média percentual de participação dos respondentes em eventos internacionais nas oito áreas do conhecimento.

Tabela 5 - Frequência de participação em eventos internacionais

\begin{tabular}{c|c|c|c|c|c|c|c|c|c}
\hline \multirow{2}{*}{ Frequência } & \multicolumn{7}{c}{ Valores obtidos (\%) } \\
\cline { 2 - 10 } & SAU & EXA & AGR & CHU & BIO & CSA & ENG & LLA & $\begin{array}{c}\text { Respondentes } \\
(\%)\end{array}$ \\
\hline 1 vez & 66,6 & 61,7 & 60,0 & 56,5 & 52,6 & 46,1 & 40,7 & 37,5 & $81(54,0)$ \\
\hline Nenhuma & 23,8 & 23,5 & 40,0 & 13,0 & 36,8 & 30,7 & 29,6 & 37,5 & $40(26,6)$ \\
\hline 2 vezes & 9,5 & 14,7 & 0 & 17,3 & 10,5 & 23,0 & 22,2 & 25,0 & $24(16,0)$ \\
\hline 3 vezes & 0 & 0 & 0 & 4,3 & 0 & 0 & 7,4 & 0 & $3(2,0)$ \\
\hline + que 3 vezes & 0 & 0 & 0 & 8,7 & 0 & 0 & 0 & 0 & $2(1,3)$ \\
\hline
\end{tabular}

Fonte: Dados da pesquisa. Elaborado pelas autoras.

Na Tabela 5, verifica-se que é expressivo o percentual de participação em pelo menos um evento internacional, destacando-se as áreas de SAU (66,6\%), EXA (61,7\%) e AGR (60\%), que obtiveram os maiores índices considerando a participação em pelo menos um evento internacional. Todas as áreas também têm participação, ainda que menor, em dois eventos anuais, com exceção da AGR. O destaque ficou por conta da área CHU, cujo percentual de $8,7 \%$ indicou participar em mais que três eventos anuais internacionais.

É importante frisar que a participação em eventos internacionais está condicionada à disponibilidade de concessão de recursos institucionais ou de agências de fomento à pesquisa para esse tipo de atividade acadêmica. Além disso, o fato de algumas áreas apresentarem baixo índice nesse quesito não implica necessariamente em desvalorizar a possibilidade de estreitamento de vínculos com pesquisadores internacionais.

\subsection{Tipos de trabalhos apresentados em eventos}

Os participantes também foram inquiridos sobre o tipo de trabalho que costumam apresentar em eventos, e a Tabela 6 apresenta os resultados obtidos 
dentre as cinco opções apresentadas.

Tabela 6 - Tipos de trabalhos apresentados nos eventos

\begin{tabular}{c|c|c|c|c|c|c|c|c|c}
\hline \multirow{2}{*}{$\begin{array}{c}\text { Tipos de } \\
\text { trabalhos* }\end{array}$} & \multicolumn{8}{c}{ Valores obtidos (\%) } \\
\cline { 2 - 10 } & ENG & SAU & CHU & AGR & CSA & BIO & EXA & LLA & $\begin{array}{c}\text { Respondentes } \\
(\%)\end{array}$ \\
\hline TCNP & 96,3 & 85,7 & 82,6 & 80,0 & 76,9 & 63,1 & 61,7 & 50,0 & $114(76,0)$ \\
\hline TRP & 55,5 & 71,4 & 52,1 & 60,0 & 76,9 & 100,0 & 61,7 & 87,5 & $102(68,0)$ \\
\hline TCP & 22,2 & 28,5 & 43,4 & 20,0 & 7,6 & 26,3 & 32,3 & 12,5 & $41(27,3)$ \\
\hline LP & 3,7 & 28,5 & 13,0 & 0 & 7,6 & 5,2 & 8,8 & 50,0 & $19(12,6)$ \\
\hline PP & 3,7 & 4,7 & 4,3 & 20,0 & 30,7 & 0 & 2,9 & 0 & $9(6,0)$ \\
\hline
\end{tabular}

Fonte: Dados da pesquisa. Elaborado pelas autoras.

(*) TCNP - trabalho com resultados completos (ou quase) de pesquisa, ainda não publicado como artigo de periódico; TRP - trabalhos com resultados parciais de pesquisas em andamento; TCP - trabalho com resultados completos de pesquisa, já publicado como artigo de periódico; $\mathbf{L P}$ - linhas de pesquisa de seu grupo; $\mathbf{P P}$ - proposta de projeto de pesquisa.

Verificou-se que o trabalho do tipo TCNP resultados completos (ou quase) de pesquisa, ainda não publicado como artigo de periódico obteve o maior escore, principalmente pelas áreas ENG e SAU. Em relação a esses achados, Lisée, Larivière e Archambault (2008, p.1783) ressaltam que "trabalhos em anais de congressos contam como uma parte significativa da literatura publicada em Engenharia”. Outro aspecto apontado pelos autores refere-se ao fato de que "além de serem publicados, trabalhos em anais de congressos são, de fato, citados pelos pesquisadores nesses campos", concluindo que:

\begin{abstract}
Embora os anais sejam responsáveis por uma parcela muito pequena da literatura pertinente na ciência como um todo, eles respondem por uma parte não desprezível da literatura citada em engenharia e ciências da computação e, portanto, devem, além dos artigos científicos, serem considerados para inclusão em estudos bibliométricos e avaliações. (LISÉE; LARIVIÈRE; ARCHAMBAULT, 2008, p. 1783, grifo nosso e tradução nossa)
\end{abstract}

A importância dos eventos para determinadas áreas foi reconhecida pela CAPES, como pode ser conferido em seu relatório de avaliação da área de Ciência da Computação:

Conforme indicado no Documento de Área, a Ciência da Computação considera tão importante quanto periódicos, os 
anais de conferências tradicionais que aceitam artigos completos e são realizadas regularmente, contando com comitês de programa e um processo rigoroso de avaliação pelos pares, semelhantemente ao usado para artigos submetidos a periódicos. (CAPES, 2013, p. 2, grifos nossos)

Em segundo lugar, com o percentual de 68\% (102 respondentes) entre as áreas, apresentou-se a tipologia trabalhos com resultados parciais de pesquisas em andamento - TRP, com destaque para a área BIO que obteve $100 \%$, seguida pela área LLA $(87,50 \%)$.

Os resultados exibidos na Tabela 6 ainda permitem verificar que a apresentação em eventos de resultados de trabalhos de pesquisa ainda em andamento (TRP) pode ser enriquecedora para a continuidade das pesquisas, pelas contribuições que os pares podem oferecer durante as apresentações. A ideia é corroborada por Meadows (1999) ao destacar a importância do feedback como um mecanismo que contribui para o pesquisador obter um retorno imediato sobre a pesquisa ainda em desenvolvimento. Esse aspecto é ratificado por González-Albo e Bordons (2011) uma vez que os eventos científicos

(...) fornecem aos cientistas uma oportunidade para apresentar e discutir os resultados preliminares de suas pesquisas e melhorar as suas redes sociais pessoais. Além disso, as conferências permitem aos cientistas ficar a par das tendências atuais de pesquisa em seu campo e aprender sobre os desenvolvimentos de ponta na sua especialidade. (GONZÁLEZ-ALBO; BORDONS, 2011, p. 369, tradução nossa).

\subsection{Tipos de participação em eventos científicos}

Os participantes da pesquisa foram demandados a identificarem o tipo de participação em eventos contendo oito tipos de participação: a) apresentador de trabalho oral; b) painelista; c) palestrante ou conferencista; d) coordenador de sessão; e) membro do comitê científico; f) membro do comitê organizador; g) ministrante de minicurso ou workshop; h) presidente ou coordenador.

Os resultados apontaram que em todas as áreas, apresentador de trabalho oral foi o tipo de participação em evento que obteve o maior escore. Os demais tipos de participação apareceram de forma decrescente na seguinte ordem: painelista, palestrante ou conferencista, coordenador de sessão, membro 
do comitê científico, membro do comitê organizador, ministrante de minicurso/workshop e presidente ou coordenador.

Os resultados obtidos em todas as oito áreas da comunidade científica investigada vão ao encontro daqueles obtidos por Jeong, Lee e Kim (2009) que conduziram um estudo para investigar se a participação em eventos acadêmicos - tais como conferências, workshops, etc. - na condição de membro de um grupo de elite, como presidente ou membro da Comissão Organizadora, presidente ou membro do Comitê Científico, moderador de sessão, palestrante convidado, ou pesquisador premiado seria benéfico para o desenvolvimento da carreira de um pesquisador. Os resultados desse estudo revelaram que os acadêmicos que participam de um grupo de elite como palestrantes têm maior destaque do que aqueles que desempenham outras funções nesses eventos.

De acordo com Meadows (1999) é esperado que poucos pesquisadores exerçam a presidência ou coordenação de um evento científico, como também sejam membro do comitê científico, membro do comitê organizador ou palestrante ou conferencista. Por sua vez, na visão de Bourdieu (2004) aqueles que exercem essas funções podem estar no topo de suas carreiras, isto é, adquiriram maior crédito científico o que lhes permite rejeitar a participação em modalidades que entendem serem menos prestigiosas.

Por sua vez, os resultados obtidos apontaram que entre os participantes da pesquisa a modalidade ministrante de minicurso ou workshop é pouco valorizada, talvez por se tratar de uma atividade de menor importância na área acadêmica e que tem sido delegada aos alunos de pós-graduação como estímulo à sua capacitação, pois de acordo com Larivière (2012) frequentemente afirmase que "os alunos de doutorado estão em uma posição intermediária, em que precisam adquirir novas habilidades e conhecimentos, mas também contribuir para o avanço do conhecimento em sua disciplina científica".

Na visão de Ziman (1993, p. 16), a experiência de doutorado pode ser traduzida como um momento de "transição psicológica de um estado de aprendizado sobre o que já se conhecia para um estado de descobertas pessoais sobre coisas que não eram anteriormente conhecidas".

Ou seja, em última instância, “(...) é durante este período de suas vidas 
que os alunos de pós-graduação se socializam na pesquisa, adquirem comportamentos, atitudes, normas e conhecimento sobre sua comunidade científica”. (LARIVIÈRE, 2012, p. 463, tradução nossa).

\subsection{Eventos científicos: validade, motivação para organização e avaliação}

Instados a responderem sobre a validade dos eventos científicos, e considerando todas as áreas, a afirmação que obteve a maior média numérica $(1,18)^{2}$ foi Mais do que um ganho científico específico, a participação em eventos é uma motivação positiva para os pesquisadores, possibilitando um aumento de sua rede de contatos, permitindo e estimulando a criatividade, além de oportunizar o direcionamento das discussões dentro de sua área de atuação.

Também foi pedido aos respondentes para se manifestarem a respeito das variáveis que influem na organização de eventos científicos, a partir de um conjunto de sete afirmações: 1) Apesar da disponibilidade de recursos oferecidos pelas agências para a organização de eventos científicos os financiamentos oferecidos pelas agências são insuficientes para cobrir os custos dos eventos; 2) Trabalhos em excesso nos eventos têm provocado diminuição do tempo de apresentações/debates; 3) A triagem de trabalhos (via resumos) é mais ágil e menos onerosa, porém compromete a qualidade da seleção; 4) Novas tecnologias (internet, videoconferências, etc.) podem promover menor custo aos participantes em evento; 5) Megaeventos e eventos com baixo público podem mudar o formato, objetivo e periodicidade dos eventos; 6) A reestruturação dos eventos científicos atuais envolve a adoção de critérios mais rígidos para seleção de trabalhos; 7) Os congressos on-line poderão substituir o atual modelo de eventos presenciais.

Dentre essas sete afirmações, a que demonstrou ser a mais significativa para todas as áreas (média 0,88) foi: Apesar da disponibilidade de recursos oferecidos pelas agências para a organização de eventos científicos, os financiamentos ainda são insuficientes para cobrir todos os custos exigidos para a realização do evento. Em contrapartida, a afirmação que obteve maior discordância (média -0,68) em todas as áreas foi Os congressos "on-line” ou 
“virtuais", que já acontecem em algumas áreas de conhecimento, poderão substituir o atual modelo de eventos presenciais que envolvem grandes investimentos e altos custos. Desse modo, embora esse modelo de evento possa ser viabilizado pelas tecnologias da informação e comunicação, tal realidade ainda não é almejada pelos participantes da pesquisa. Talvez isso se deva à valorização do contato presencial e também pelo fato de que a concretização dos colégios invisíveis ocorre em ambientes paralelos aos do evento, situações não formais como um "cafezinho", uma "noite de autógrafos", "almoços" e “jantares" etc. Isso reforça a importância do contato e a interação pessoal presencial entre especialistas para a discussão sobre pesquisas e trabalhos em desenvolvimento nas diversas áreas do conhecimento.

Visando perquirir a opinião dos participantes da pesquisa sobre a avaliação dos eventos científicos foi apresentado a eles uma questão hipotética: Se você fosse designado para avaliar a solicitação de apoio a um evento no País, e solicitado que se manifestassem sobre o grau de importância que atribuem a alguns quesitos para concessão do financiamento solicitado. Para todas as áreas as três afirmações que obtiveram maior grau de importância foram Importância do evento para a área que alcançou uma média de 1,6, Qualificação do comitê científico, com a média de 1,5 e Critérios de avaliação dos trabalhos, com a média 1,5. Inversamente, as afirmações que receberam menor grau de importância dos respondentes de todas as áreas foram Qualificação da Comissão Organizadora, com média de 1,1 e Qualificação do Coordenador do evento, com a média 1,2.

Em outra questão os participantes foram solicitados a se manifestarem sobre o grau de importância das condições que os eventos científicos devem cumprir para o recebimento de apoio pelas agências de fomento. Os resultados obtidos $^{3}$ revelaram que as duas condições de avaliação apresentadas e consideradas mais importantes para as áreas são Divulgar a geração de novos conhecimentos e produtos (média 2,4) e Promover e elevar a qualidade da produção científica e tecnológica (média 2,7). Inversamente, as duas condições menos importantes para as áreas são Ser de âmbito local, estadual, regional, nacional ou internacional (média 4,6) e Ser de relevância para o sistema de 
pós-graduação no país, com a média 4.

\subsection{Turismo e megaeventos científicos}

Ao conversar, ainda que informalmente, com pesquisadores e pós-graduandos, é recorrente entre eles a visão de que participar de eventos constitui em uma valiosa oportunidade para que se conheçam novos lugares. Assim, a sondagem da opinião dos participantes sobre esse assunto foi realizada na pesquisa por meio da afirmação de que o fato da sede do evento ser em cidade turística é uma motivação mais forte para a participação no evento do que a própria divulgação da pesquisa. As médias obtidas demonstraram que a escolha da cidade é um fator relevante para as áreas de EXA $(1,12)$, CSA $(1,08)$, BIO $(1,05)$ e ENG $(1,04)$, e de menor importância para as áreas de CHU $(0,52)$, AGR $(0,60)$, LLA $(0,75)$ e SAU $(0,71)$. Os comentários de Giami $(2009$, p. 187, tradução nossa) de que "as conferências também são momentos de afastamento da vida diária; elas permitem descobrir lugares pitorescos, visitar museus, ir a concertos" não descartam também as oportunidades adicionais oferecidas aos participantes em eventos, sugerindo que a escolha de cidades para a realização de eventos científicos é uma decisão estratégica da comissão organizadora do evento.

Recentemente algumas áreas já lançam mão de recursos alternativos para a realização de eventos, como é o caso dos cruzeiros marítimos. Essa modalidade de evento científico "sui generis" segundo os organizadores visa incrementar a participação de pesquisadores combinando a atividade científica com o lazer. O VII Congresso da Fundação Otorrinolaringologia, por exemplo, foi realizado pela primeira vez a bordo de um navio, e na divulgação do evento, a chamada explicava:

O Congresso da Fundação Otorrinolaringologia será a bordo do Costa Mágica, onde atualização científica e profissional de excelência será mesclada com grandes momentos de descontração, contato profissional e entretenimento entre otorrinolaringologistas, fonoaudiólogos, parceiros da indústria farmacêutica e empresas correlatas. Por isso o evento não será só um congresso nem um simples cruzeiro de navio, mas sim um grande marco dentro dos nossos eventos científicos. Você também poderá levar sua família e 
convidar seus amigos a viajar conosco. A embarcação sai do Porto de Santos, para em Ilha Bela - onde os passageiros poderão descer e visitar a cidade - e segue para Búzios - ficando atracada por dois dias, permitindo também uma programação de passeios em terra. $\mathrm{Na}$ volta, o navio fará uma parada estratégica na Baia de Copacabana, quando será realizado o jantar de encerramento do evento. (CONGRESSO, 2008, grifos nossos).

Em 2011, o IV Congresso da Academia Brasileira de Especialistas em Enfermagem também foi realizado a bordo de um navio. Com o sugestivo tema de "Navegar nas dimensões: Cuidar, Ensinar, Pesquisar e Gerenciar" a convocatória do evento conclamava a participação dos pesquisadores informando que

O Congresso será realizado a bordo do navio Costa Fortuna, em um cruzeiro de quatro noites navegando pelos litorais de São Paulo, Rio de Janeiro e Santa Catarina. Com o objetivo de proporcionar aos participantes um evento científico com inúmeras vantagens: a possibilidade de um encontro do mais alto nível, com troca de experiências entre os profissionais, integração entre congressistas e organizações e momentos de lazer. (CONGRESSO, 2011, grifos nossos).

Com relação à realidade atual dos eventos científicos (megaeventos) a afirmação o excesso de atividades fragmenta o evento apresentando rotatividade de público nos recintos das reuniões obteve a maior média entre todas as áreas $(1,19)$; o maior destaque foi para a área CSA $(1,54)$, seguida por SAU $(1,38)$ e BIO $(1,37)$, enquanto que a menor média foi obtida pela área AGR $(0,80)$. Constata-se que, geralmente nos grandes eventos científicos ocorrem inúmeras atividades paralelas, levando os congressistas a fazerem opções, pois não é possível participar de todas as atividades que eles almejariam, uma vez que são inúmeras conferências, mesas redondas, sessões de apresentações orais e de pôsteres, atividades culturais, contatos informais, etc. a serem realizados.

A afirmação A contratação de empresas na organização de eventos tem causado impacto nas taxas de inscrição que se tornaram mais elevadas foi a segunda média das áreas considerada como mais importante, com destaque para as áreas de AGR (média 1,20), BIO (média 1,16) e SAU (média 1,14). Tais resultados nos levam a inferir que a organização de eventos nessas áreas já está em um nível de profissionalização mais avançado, mas repercutindo em inscrições mais onerosas. 
Outro aspecto que pode refletir no custo total do evento está relacionado às quantias importantes destinadas a cobrir custos de infraestrutura (hotéis, centros de convenção, etc.) e também de serviços necessários (cerimoniais, transporte de convidados, secretaria, intérpretes, etc.) o que acaba por acarretar um aumento significativo nas taxas de inscrição. A esse respeito foi proposta a afirmação: Em determinadas áreas de conhecimento, é cada vez maior o número de eventos científicos organizados por Associações e Sociedades científicas. Esse fato permite o reforço de notoriedade e imagem institucional dos organizadores. Em geral, todas as áreas concordaram que essa prática já está presente no mundo acadêmico. Há que se considerar ainda que os eventos são fonte de recursos para as instituições envolvidas na sua promoção, além de oferecerem visibilidade para as mesmas e para os pesquisadores envolvidos nessa atividade. Tais fatos confirmam as características históricas dessas Sociedades e Associações que desde a fundação da Royal Society, na Inglaterra e da Académie de Sciences, na França, no século XVII, cumprem o importante papel de promover o desenvolvimento da ciência por meio da disseminação de conhecimentos produzidos.

Em relação à afirmação Nesses eventos, algumas atividades são esvaziadas e muitas vezes contam com poucos participantes na plateia além do palestrante elou expositor do trabalho oral, as áreas CSA (média 1,31) e LLA (média 1,25) foram as que mais concordaram com a afirmação. As áreas AGR $(0,40)$ e SAU $(0,71)$ obtiveram médias menores, o que talvez possa sinalizar que essas áreas enfrentam menos esse tipo de problema.

De todo modo, o esvaziamento de alguns eventos pode ser atribuído a vários fatores, tais como: a) o excesso de atividades desenvolvidas pelos pesquisadores - o ensino, a extensão e administração universitárias -, impossibilitam sua participação integral em um evento científico; b) as reuniões em petit comité de membros do "colégio invisível” ocupam um considerável tempo durante o evento; c) a existência de atividades paralelas em um evento, tais como palestras, conferências, minicursos concorrem com as apresentações de trabalhos; d) o apelo ao "turismo científico", que atua como uma válvula de escape da rotina acadêmica e diminui o envolvimento com o evento 
propriamente dito. Além disso, o esvaziamento das sessões não pode ser atribuído apenas ao congressista, pois este ao apresentar o seu trabalho cumpre uma das fases do ciclo da comunicação científica. A diminuição das audiências, além dos fatores já apontados, acaba por reproduzir o comportamento de pesquisadores "seniores" entre os "novatos" os quais se limitam a apresentar o seu trabalho e não participar de outras atividades.

A ocorrência desse fato tem levado os congressistas a priorizarem determinadas atividades em detrimento de outras não menos importantes. Nesse sentido, compete à comunidade científica refletir sobre o fenômeno dos megaeventos, pois atualmente este tipo de evento ocorre com bastante frequência em várias áreas de conhecimento.

\section{Considerações Finais}

Os resultados obtidos na pesquisa evidenciaram um conhecimento importante sobre inúmeros aspectos do significado dos eventos científicos para diferentes áreas de conhecimento da comunidade científica pesquisada. A pesquisa realizada mostrou que os eventos científicos ainda são um dos meios de divulgação mais utilizados pelos cientistas e pesquisadores. Mesmo quando se trata de divulgar projetos de pesquisa, e/ou resultados iniciais e parciais, os eventos ainda se constituem em um bom termômetro para verificar a aceitação pelos pares.

Resgatando o modelo de Garvey e Griffith (1979) que aponta a existência de dois tipos de comunicação - a informal e a formal -, os eventos científicos devem continuar cumprindo importante papel na etapa informal da comunicação científica, embora as publicações de trabalhos completos e resumos apresentados nos eventos não tenham o mesmo status de outros tipos de publicação oriundos dos canais formais, especialmente artigos científicos. Finalmente, ao demonstrar que a visão sobre os eventos científicos é diferente para cada área de conhecimento, os achados da pesquisa mostraram que as áreas de conhecimento definem o seu público alvo privilegiado aos quais se destinam 
os resultados da pesquisa.

\section{Referências}

BARUCH, Y. Response rate in academic studies: a comparative analysis.

Human Relations, Thousand Oaks, v. 52, p. 421-438, 1999.

BOURDIEU, P. Os usos sociais da ciência: por uma sociologia clínica do campo científico. São Paulo: UNESP, 2004.

CAPES. Relatório de avaliação 2010-2012, trienal 2013 - Ciência da

Computação. Brasília, 2013. Disponível em:

$<$ https://docs.google.com/viewer?a=v\&pid=sites\&srcid=Y2FwZXMuZ292LmJ yfHRyaWVuYWwtMjAxM3xneDoxMTdkMTgxYjVjN2M4OTk0>. Acesso em: fev. 2016.

CONGRESSO DA ACADEMIA BRASILEIRA DE ESPECIALISTAS EM ENFERMAGEM, 4, 2011. Santos-SP (Offshore). Disponível em: <http://www.abenmt.org.br/Programacao_ABESE.pdf > Acesso em: jan. 2016.

CONGRESSO DA FUNDAÇÃO OTORRINOLARINGOLOGIA, 7, 2008. Rio de Janeiro-RJ (Offshore). Disponível em:

<http://www.forl.org.br/Noticia/ViewNoticia/843> Acesso em jan. 2016.

COZBY, P. C. Métodos de pesquisa em ciências do comportamento. São Paulo: Atlas, 2003.

CRANE, D. Invisible colleges. Chicago: University of Chicago Press, 1972.

CUNHA, H. F. R. S.; SALLUH, J. I. F.; FRANÇA, M. de A. Atitudes e percepções em terapia nutricional entre médicos intensivistas: um inquérito via internet. Revista Brasileira de Terapia Intensiva, São Paulo, v. 22, n. 1 p. 5363, 2010.

GARVEY, W. D. Communication: the essence of science. London, New York: Pergamon, 1979.

GARVEY, W. D.; GRIFFITH, B. C. Scientific communication as a social system. In: GARVEY, W. D. Communication: the essence of science. London, New York: Pergamon, 1979. p. 148-164.

GIAMI, A. Ethnographie d'une conférence médico-scientifique: l'influence de l'industrie pharmaceutique dans le champ de la sexologie, Revue Sociologie Santé, Bourdeaux, v. 30, p. 187-210, 2009. 
GONZÁLEZ-ALBO, B.; BORDONS, M. Articles vs. proceedings papers: Do they differ in research relevance and impact? A case study in the Library and Information Science field. Journal of Informetrics, Leiden, v. 5, p. 369-381, 2011.

\section{GUIMARÃES, V. A. L. A comunidade científica da UFSCar e a}

comunicação da ciência: um estudo sobre o significado dos eventos científicos. Dissertação (Mestrado em Ciência, Tecnologia e Sociedade) - Programa de PósGraduação em Ciência, Tecnologia e Sociedade, Universidade Federal de São Carlos, São Carlos, 2012.

GÜNTHER, H. Pesquisa qualitativa versus pesquisa quantitativa: esta é a questão. Psicologia: teoria e pesquisa, Brasília, v. 22, n. 2, p. 201-210, maioago. 2006.

JEONG, S.; KIM, H.-G. Intellectual structure of Biomedical Informatics reflected in scholarly events. Scientometrics, Amsterdam, v. 85, n. 2, p. 541551, Feb. 2010.

JEONG, S.; LEE, S.; KIM, H.-G. Are you an invited speaker? A bibliometric analysis of elite groups for scholarly events in Bioinformatics. Journal of the American Society for Information Science and Technology, New York, v. 60, n. 6, p. 1118-1131, 2009.

LARIVIÈRE, V. On the shoulders of students?: the contribution of $\mathrm{PhD}$ students to the advancement of knowledge. Scientometrics, Amsterdam, v. 90, n. 2, p. 463-481, 2012.

LISÉE, C.; LARIVIÈRE, V.; ARCHAMBAULT, É. Conference proceedings as a source of scientific information: a bibliometric analysis. Journal of the American Society for Information Science and Technology, New York, v. 59, n. 11, p. 1776-1784, 2008.

MARTENS, B.; SARETZKI, T. Conferences and courses of biotechnology: describing scientific communication by exploratory methods. Scientometrics, Amsterdam, v. 27, n. 3, p. 237-260, 1993.

MEADOWS, A. J. A comunicação científica. Brasília: Briquet de Lemos Livros, 1999.

PRICE, D. J. de S. Science since Babylon. New Haven: Yale University Press, 1961.

SHEEHAN, K. B; HOY, M. G. Using e-mail to survey internet users in the United States: methodology and assessment. Journal of Computer Mediated Communication, New York, v. 4, n. 3, 1999.

SHIH, T.-H.; FAN, X. Comparing response rates from web and mail surveys: a 
meta-analysis. Field Methods, Beverly Hills, v. 20, n. 3, p. 249-271, 2009.

SÖDERQVIST, T.; SILVERSTEIN, A. Participation in scientific meetings: a new prosopographical approach to the disciplinary history of science: the case of immunology, 1951-1972. In: SCANLON, Eillen; HILL, Roger; JUNKER, Kirk (Eds.). Communicating science: professional contexts. London: Routdlege, 1999. p. 101-131.

SÖDERQVIST, T.; SILVERSTEIN, A. Studying leadership and subdisciplinary structure of scientific disciplines. Scientometrics, Amsterdam, v. 30, n. 1, p. 243-258, 1994.

WEIBLE, R.; WALLACE, J. Cyber research: the impact of the internet on data collection. Marketing Research, Chicago, v. 10, n. 3, p. 19-24, Fall 1998.

WU, Y. W. et al. The influencing factors of commitment and business integration on supply chain management. Industrial Management \& Data Systems, Wembley, v. 104, n. 4, p. 322-333, 2004.

ZIMAN, J. M. Competition undermines creativity. The Times Higher Education, London, Suppplement, p. 16, 16 July 1993.

ZIMAN, J. M. Real science: what it is and what it means. Cambridge: Cambridge University, 2000.

\title{
The communication of science in scientific events in researcher's vision
}

\begin{abstract}
This paper shows the results of an empirical research about the significance that scientific events take for a community of researchers from different science areas. From a methodological point of view, this is an exploratory and descriptive study, with a quantitative and qualitative approach. The investigated population was composed by 150 researchers linked to a federal institution of higher education located in the state of São Paulo (Brazil). The methodology used to collect data was an online questionnaire. Empirical research data were categorized and analyzed in the light of the theoretical framework of the Sociology of Science and Information Science. The results showed specificities of different areas of knowledge regarding scientific communication events, but confirms that they still are one of the media most used by researchers and constitute a good thermometer to check the peer review acceptance.
\end{abstract}

Keywords: Scientific events. Communication of science. Sociology of science. Informal communication. Scientific divulgation. 
Recebido: 22/03/2016

Aceito: 24/05/2016

${ }^{1}$ Como se trata de um recorte de uma pesquisa mais ampla (GUIMARÃES, 2012) optou-se nesse artigo por focalizar apenas as respostas obtidas nas questões que compuseram a seção B do questionário. As demais questões serão discutidas em outro artigo.

${ }^{2}$ Para mensurar o grau de concordância ou discordância dos participantes em relação a afirmações que representaram construtos teóricos da pesquisa foi utilizada a Escala de Likert. Esse tipo de escala permite que os respondentes se posicionem de acordo com uma medida de concordância ou discordância atribuída ao item e, de acordo com a resposta, se infere a medida do construto. Apesar das diversas discussões a respeito do número de ideal de categorias da Escala de Likert optou-se pelo número de cinco na pesquisa realizada. Para contabilização das respostas foram atribuídos valores numéricos às variáveis nominais expressas por meio de critérios de opinião (concordância/discordância), de ocorrência do fenômeno, e de importância em relação a determinados aspectos dos construtos teóricos da pesquisa. Ou seja, para o cálculo da média os valores nominais da escala foram substituídos por valores numéricos. Por exemplo, "concordo totalmente" (+2); "concordo" (+1); "indiferente" (0); "discordo" (-1); "discordo totalmente" (-2). Assim, as médias numéricas positivas indicam concordância e as negativas, discordância.

${ }^{3}$ Nessa questão os pesquisadores tinham que atribuir um grau de importância em uma escala de valores que variou entre 1 "muito importante" a 6 "menos importante", portanto, nesse caso, quanto menor a média, mais importante a condição, uma vez que se tratou de uma questão de ranking. 